\title{
DEVELOPMENT OF HEAVIER-THAN-AIR CRAFT
}

\author{
By The Right Hon. J. T. C. Moore-Brabazon, P.C., M.P. \\ Minister of Aircraft Production
}

G LIDING flight, so patent to all watchers of Nature, seems to have been neglected through all the ages. There was little reason why efficient gliders could not have been constructed with the materials at the hand of many preceding generations, and had this been pursued with vigour the high-efficiency glider might well have come into use and the motive power required deduced therefrom to get sustained flight. The early pioneers of gliding flight never reached a glide of one in ten, but Lilienthal, Chanute and others were getting near that angle when the Wright brothers with their flexible biplane, controlled fore and aft aerodynamically instead of by transference of weight, showed a real advance in stability and the possibility of the introduction of an engine.

December 17, 1903, marks indeed a very great day in human progress and no credit is too high to pay the two Wright brothers for the tremendous concentration that they must have devoted to the construction of this machine, for not only did they construct the actual machine but also in fact, built an engine — no mean feat-which after gearing down by chains to two large-sized propellers, gave the necessary propulsive power to sustain flight. It is interesting to note that in the Wrights' patent their claim was for lateral stability. By gliding experiments they had found that putting extra warping on the depressed wing did not restore the aeroplane or glider to horizontal unless it was accompanied by rudder to force it to maintain its speed. The control for this was complicated, the rudder and side control being put on one lever, which was soon, however, found inconvenient. What is remarkable is the hiatus between the original experiments at Kitty Hawk and the demonstration of sustained flight which the Wright brothers gave in the United States and in Europe as late as 1908five years. This latter machine, judged by the original which is now in the Science Museum, had become more robust, the under-carriage stronger and the engine more powerful, but generally the same scheme was adopted with the tiresome launching sy virtue of reposing the machine upon-so to speak-a typa of sleeper on roller skates which ran down a single rail pointed in the direction from which the wind was coming. Acceleration down this rail was accentuated by a weight hoisted in a pylon falling, it being attached round the end of the rail through a pulley and back to the machine. Acceleration to about 45 m.p.h. was obtained in
$90 \mathrm{ft}$. by virtue of the kinetic energy of the weight and push of the propellers.

Analogous experiments had been proceeding in Europe. Santos Dumont had obtained a fight of about 100 metres with a vast dihedral biplane with no lateral control, of a very big box type with control in pitch for'ard. This flight took place in 1906. The propelling power was a very remarkable engine built by Levavasseur, a genius in design. The propeller was coupled to the engine shaft, but the engine was very remarkable for those days. It was an eight-cylinder $\mathrm{V}$ type. It had copperdeposited water jackets and fuel injection-an engine in fact twenty years ahead of its time. It was with this engine, however, that Farman in Paris with a biplane built by Voisin, again with no side control but with a stabilizing tail and single horizontal rudder in front, won the Archdeacon prize for a sustained flight of a kilometre in 1908 . I flew several of this type ; they were unstable in pitch and laterally uncontrolled.

The only outstanding aeroplane in those days from an aerodynamic point of view was the Antoinette, which was flown by Latham. Here again Levavasseur designed not only the engine but also the aeroplane, introducing steam cooling, a thing we have not yet reached in modern practice. This machine in its day was, I think, the most graceful, being a centrally winged monoplane, and it was a pity that it did not go down in history as the first machine to cross the Channel, as twice Latham failed by a matter of a few hundred yards.

There was a general attack upon flight in Europe by a succession of more and more powerful engines on singularly inefficient aircraft; exception might perhaps be made to the Bleriot, a light type of monoplane with warping wings, open fuselage and tractor screw. This historical craft that crossed the Channel was driven by an Anzani threecylinder engine, but never again did this engine or one of similar type run for such a long period as when crossing the Channel, the reason being that it was kept cool and avoided overheating by virtue of a rain-storm which cooled it !

The next important contribution along the lines of excessive power rather than aerodynamic efficiency was the introduction of the radial engine of a rotating type, not the non-rotating radial as we see to-day. This was the famous Gnome engine. It had seven cylinders, exhaust valve on the top, and gave roughly about 40 h.p. 
at 1,100 revs. per min. At first the amount of lubricating oil that was wasted by escaping centrifugally through the exhaust valve made the consumption of lubricating oil almost equal to that of the petrol. Somebody cleverly suggested the use of castor oil, which has the peculiarity of getting stickier the hotter it gets, and from that moment there existed an engine which was certainly comparatively reliable and successful.

Many remarkable flights were made with this engine, including the first London to Manchester by Paulhan and the glorious failure by Graham. White in the same competition. This was a great engine which contributed very much towards flight in Europe. Speeds, of course, had increased by now-and I am referring to 1910-11-from about 45 m.p.h. to 60 and 70 m.p.h. and the general trend was towards the monoplane type of construction in order to avoid parasitic drag. Seaplanes had come in by now and the Schneider Cup - the blue ribbon of seaplane racing-was won by that type of machine. The monoplane fetish was, however, completely upset by Tommy Sopwith's attack on the Schneider Cup, when he appeared with a biplane (1914) and had at least thirty-five miles up his sleeve. Again we were back to biplanes.

No great advance from the point of view of useapart from exhibition-had been made until the outbreak of the War of 1914-18 when there was a tremendous concentration, regardless of economy or anything else except the war outlook, on aircraft in general. Some very remarkable machines and engines were constructed under pressure during that War. Machines jumped in horse-power from 50 to nearly 500, and they were exceeding 120 m.p.h. towards the end with regularity. The outstanding machines of the War were the Bristol Fighter, a biplane fighter-reconnaissance machine as we would call it now, two-seater, with engine, a Rolls, rather high up between the two planes; the Handley Page big bomber; and among fighters, the S.E.5, Sopwith Pup and the Camel. It is interesting to note that the 'pusher' type of machine was still favoured by some. The general trend of engine design on the British side at any rate was the multi-cylindered type, whilst the Germans concentrated on big six-cylinder units in line. The mushroom growth of aviation forced upon the world by war caused a very great reaction afterwards. Great Britain threw away her predominance in the air, and there was not very much imagination shown towards the possibility of joining the Empire closer together in time by virtue of flight.

Holt Thomas certainly had vision but no machines. $\mathrm{He}$ endeavoured to run a service to Paris and elsewhere on the Continent with old war machines, but the enterprise failed. But the idea that civil aviation had a future was born never to be killed. Generally it was realized, however, that civil aviation could not, in the words of the present Prime Minister speaking at that time "fly by itself", and subsidies throughout the world were started in order to foster civil aviation. But most nations spoke with their tongue in their cheek because fostering civil aviation meant, in fact, fostering an aviation industry built to make war machines. In fact some countries deliberately used war machines for civil purposes in order to find a use for them. Germany developed a very intensive internal non-economical commercial service in that they were not allowed war machines, but they were potential war machines. Great Britain started building two-engined heavy machines, but of vast surface with light wing loading-notably the Heracles built by Handley Page, slow, but a reliable money-making attempt at civil aviation.

However much various governments strove to get advanced with the ideal bomber, the real advance in aviation and especially in civil aviation came from the intense local competition which was being waged in the United States-a country ideally situated for long-distance air transportamong the various companies operating there in conjunction with manufacturing units.

Just as the Mercedes car suddenly emerged upon the motoring world five years ahead of anything else, so in aviation the Douglas machine marks an epoch in development. Here for the first time we had a machine completely clear of extraneous speed-reducing impediments. It was a skinstressed machine, twin engine, tractor, of beautiful lines and of great comfort, and had three outstanding aerodynamic advantages: first of all the variable pitch propeller, which enabled it to get off with little run by virtue of low gearing the propellers and after attaining height increasing the pitch. It had a retractable under-carriage which in the realms of $200 \mathrm{~m} . \mathrm{p} . \mathrm{h}$. meant a very great saving in drag and increased the speed for power. It had flaps which enabled the machine when they were depressed to take up a very coarse gliding angle, and allowed a machine so beautifully faired to come to rest in quite a small field, without running on. This machine was built ostensibly to serve the world, but is to-day the prototype for every long-range bomber. It is indeed a tragedy that a machine designed entirely for civil purposes should turn out in fact to be the ideal long-range bomber.

The radial engine and the liquid-cooled still continued to fight their battle for supremacy. The horse-power now is in the range of 2,000 and weights round about a pound per horse-power. Liquid coolers have the advantage of small frontal area ; radials are simpler by virtue of air cooling. Height has now become a necessary part of engine 
design, and here we find that it is not a function of power alone but of maintaining power at height by boost. Various boosts have been introduced on engines varying between the two-stage, two-speed blower, to the exhaust-driven turbine type.

I suggest that the future economical cruising stratum will be in the neighbourhood of $35,000 \mathrm{ft}$. If that is to be the right level then passengers cannot be asked to put up with the barometer at less than 6 in., so that pressurized cabins suitably heated and pressed will become the standard order of the commercial machine.

Long-range bombers have drifted into the fourengined type of great reliability with speeds up to 300 m.p.h., but they are voracious petrol eaters. Single-seater fighters with engines of 2,000 horsepower with wings not too heavily loaded, so that manœuvrability is not impaired, exceed the 400 m.p.h. mark. That is where we are to-day.

How all this is to be exploited for the benefit of inter-communication afterwards is difficult at present to say, and it is not clear how loads can in fact yet pay. We have perhaps come to the definite end of a type again, and it is not certain whether the tractor will eventually survive against the pusher, or whether present power units, with their big disk area propellers, are the end of the story. Aeronautics is now a science and development will not stop. There are great possibilities looming ahead, revolutionary in character ; but the present situation may be prolonged by a great increase in wing loading with assisted take off.

Here is a brief résumé of the results of those first experiments by the Wrights. (Mr. Orville Wright celebrated his seventieth birthday on August 19. See Nature of August 16, p. 191.) It is indeed the duty of man to see that what the Wrights first introduced-one of the greatest inventions and contributions to mechanical science-is eventually used for the benefit of the world and not for the destruction of civilization. We cannot blame the Wright brothers for the prostitution of their invention that has taken place. Those of us who knew the two brothers will always cherish affection for them and the memory of two remarkably quiet, charming people. It will be for succeeding generations to prove that they introduced into the world, not a curse, but a means of transport which will eventually bind nations together on a basis of mutual understanding and goodwill.

\title{
CROP DAMAGE BY AIR ATTACK
}

\author{
By Sir John Russell, F.R.S. \\ Rothamsted Experimental Station
}

$\mathrm{T}$ WO possibilities of damage to crops by enemy action are now so near that warnings have been issued along with instructions showing what is to be done should the necessity for action arise. The Ministries of Home Security and of Agriculture have sent out to farmers three leaflets giving simple but precise methods for coping with attempts to destroy our crops either by fire or by poison gas.

In regard to fire, the problem is an old one in Australia and in Canada, so that a certain amount of experience is already available. In both countries the prairie or bush regions are liable to become very dry during periods of drought, and a spark or even a cigarette end may start a conflagration that races over miles of country, causing havoc wherever it goes. I shall never forget the Australian bush fires in the summer of 1938-39 (December and January); they were impressive beyond words, and one marvelled at the skill and courage of the Australians in facing up to what seemed irresistible devastation, gradually limiting and finally subduing it. In Great Britain experience is far more limiter, and except for occasional fires started by picnickers or campers in young forestry plantations, the only fires ever. seen in British fields are those caused by sparks from railway engines. But, small as it is, this experience is invaluable at the present time, and has clearly been drawn upon in the preparation of these pamphlets.

The reason so few field or forest fires are seen in Great Britain is, of course, the unsuitability of the climate. Occasionally, it is true, we get a summer where crops and grass dry up and look as if they would burn easily. 1940 was an example, and it is fortunate for us that the Germans made no large-scale attacks then. 1941 has been much wetter, and nothing could have fired the crops this summer. In spite of this, however, the Ministries are taking no risks, and are issuing instructions should the case arise.

Greenleaf crops are obviously exempt from risk, and the only danger might come to cereals. Oats are usually cut before they are dead ripe, and they normally still contain so much sap as to be noncombustible ; no danger arises from railway-engine sparks, and it may be assumed that incendiary 